\title{
Produção do girassol e teor de óleo nas sementes em diferentes épocas de semeadura no Centro-Sul do Paraná
}

\author{
Sunflower yield and oil seed content at different sowing dates in the southern central region of \\ Paraná state
}

\author{
Giovani Luiz Thomaz $^{\mathrm{I}}$ Jeferson Zagonel $^{\mathrm{II}}$ Luiz Osvaldo Colasante ${ }^{\mathrm{III}}$ Ranieri Ramos Nogueira
}

\section{RESUMO}

O presente estudo teve o objetivo de avaliar o efeito de dez épocas de semeadura na produção de aquênios, no teor de óleo dos aquênios e, como consequência, na produção de óleo em quatro cultivares de girassol em Ponta Grossa, PR. Dessa forma, foram conduzidos dez experimentos em intervalos de 20 dias, com início em 30/07/2007 e término em 28/01/2008. Cada experimento constituía uma época de semeadura $e$, para verificar a normalidade dos erros $e$ homogeneidade das variâncias, inicialmente, realizou-se uma análise individual por experimento para, em seguida, realizar análise conjunta. O delineamento experimental utilizado foi o de blocos ao acaso com quatro tratamentos e quatro repetições, em cada época de semeadura. Entre épocas de semeadura e cultivares, houve interação para todas as variáveis estudadas, sendo que as maiores produções de aquênios e de óleo ocorreram nas semeaduras do final de julho, mês de agosto $e$ de setembro. O teor de óleo dos aquênios foi maior nas primeiras épocas de semeadura, diminuindo nas épocas mais tardias, enquanto as maiores produções de aquênios foram obtidas com as cultivares 'M734' e 'Aguará 4'.

Palavras-chave: Helianthus annuus, produção de aquênios, produção de óleo.

\section{ABSTRACT}

The objective of this research was to evaluate the effect of ten sowing date on achenes yield, on achenes oil content $s$ and, as a consequence, on oil yield in four cultivars of sunflower. Ten experiments were carried out at Ponta Grossa, $P R$, Brazil, with intervals of 20 days, beginning on July 30 , 2007 and finishing on January 28, 2008. Each sowing time constituted an experiment. The experiments were arranged in a randomized complete block design, with four treatments (cultivars) and four replicates. It was performed the analysis of variance of each experiment separately and, after that, the joint analysis of all experiments. There was interaction between sowing date and cultivars for all the studied variables. The highest achenes yield $s$ and oil occurred at the end of July, in August and in September. The achenes oil content was higher in the earlier sowing dates, decreasing in the later sowing dates. The cultivars 'M734' and 'Aguará 4' had the highest achenes yield.

Key words: Helianthus annuus, yield of achenes, oil yield.

\section{INTRODUÇÃO}

O Programa Nacional do Biodiesel, criado pela lei 11.097/2005, determina que a partir do ano de 2013 será obrigatória a adição de 5\% de biodiesel ao óleo diesel consumido no Brasil, criando um mercado de cerca de 2,5 bilhões de litros de biodiesel ao ano, tornando necessário o aumento da oferta global de óleos vegetais nos próximos anos. Dentre as plantas oleaginosas com potencial para a produção de biodiesel, o girassol tem as seguintes características desejáveis: elevado teor de óleo, cultivo com menor exigência hídrica, bom potencial produtivo e possibilidade de adequar-se em sistemas de produção sem competir com a cultura principal (GAZZONI, 2005).

A produção de aquênios, o teor de óleo deles e a produção de óleo do girassol dependem da

IInstituto Agronômico do Paraná (IAPAR), CP 129, 84001-970, Ponta Grossa, PR, Brasil. E-mail: gthomaz@iapar.br. *Autor para correspondência.

IUniversidade Estadual da Ponta Grossa (UEPG), Ponta Grossa, PR, Brasil.

IIIAPAR, Londrina, PR, Brasil. 
temperatura do ar, precipitação pluvial e radiação solar incidente na cultura, assim como a escolha da época de semeadura permite que haja condições ambientais favoráveis durante o seu desenvolvimento, diminuindo a probabilidade de frustração de safras (AGUIRREZÁBAL et al., 2001). No Centro-Sul do Paraná, o girassol pode ser semeado a partir do início de agosto (IAPAR, 2009b), enquanto que as demais espécies cultivadas na região são semeadas a partir de meados de setembro. No entanto, há carência de informações sobre o comportamento de genótipos dessa oleaginosa, semeados em épocas distintas, sendo um dos fatores que prejudica a expansão da cultura na região.

O objetivo deste trabalho foi avaliar o efeito de dez épocas de semeadura na produção de aquênios, no seu teor de óleo e, como consequência, na produção de óleo, em quatro cultivares de girassol, na região Centro-Sul do Paraná.

\section{MATERIAL E MÉTODOS}

Os experimentos foram instalados na Estação Experimental do IAPAR em Ponta Grossa, PR, localizada entre as coordenadas $25^{\circ} 09^{\prime} 50^{\prime}$ 'S e $50^{\circ} 09^{\prime}$ 10” W, altitude de 823 metros, cujo clima é classificado segundo Köppen como Cfb, ou seja, clima temperado propriamente dito, com temperatura média no mês mais frio abaixo de $18^{\circ} \mathrm{C}$ (mesotérmico), verões frescos, temperatura média no mês mais quente abaixo de $22^{\circ} \mathrm{C}$ e sem estação seca definida (IAPAR, 2009a). A precipitação média anual é de 1.600 a $1.800 \mathrm{~mm}$, com o trimestre mais chuvoso (dezembro, janeiro e fevereiro) com média de 500 a 600mm e, o mais seco (junho, julho e agosto) com média de 250 a 350mm.

O solo do local do experimento é classificado como LATOSSOLO VERMELHO Distrófico, textura argilosa, fase relevo suave ondulado (SANTOS et al., 2006). A análise química do solo da camada de zero a $0,2 \mathrm{~m}$ foi realizada antes da implantação dos experimentos, resultando em 2,1 $\mathrm{mg} \mathrm{dm}^{-3} \mathrm{de} \mathrm{P}$ (Mehlich); 28,85 $\mathrm{dm}^{-3}$ de C; pH 5,2; zero de saturação por Al; 4,9 $\mathrm{cmol}_{\mathrm{C}} \mathrm{dm}^{-3}$ de Ca; 3,3cmol $\mathrm{dm}^{-3}$ de $\mathrm{Mg} ; 0,23 \mathrm{cmol}_{\mathrm{c}}$ $\mathrm{dm}^{-3}$ de K (Mehlich) e saturação por bases de 63\%.

O delineamento experimental foi de blocos ao acaso com quatro tratamentos (cultivares 'Catissol', 'M734', 'Hélio 250’ e ‘Aguará 4') em quatro repetições. Em intervalos de 20 dias, um novo experimento foi implantado, constituindo as épocas de semeadura, denominadas $E_{1}, E_{2}, E_{3}, E_{4}, E_{5}, E_{6}, E_{7}, E_{8}, E_{9}$ e $E_{10}$ semeadas, respectivamente, nos dias 30/07/2007, 17/ 08/2007, 05/09/2007, 24/09/2007, 17/10/2007, 07/11/2007, 27/11/2007, 18/12/2007, 07/01/2008 e 28/01/2008. Cada parcela foi constituída de quatro linhas de $7 \mathrm{~m}$ de comprimento espaçadas de $0,7 \mathrm{~m}$, sendo a densidade de 3,3 plantas por metro linear, equivalente a 47.142,8 plantas ha-1. As avaliações ocorreram nas duas linhas centrais de cada parcela e as cultivares escolhidas são amplamente usadas em outros locais, porém não foram testadas e avaliadas na região.

No momento da semeadura de cada época, foram distribuídos e incorporados manualmente nos sulcos $10 \mathrm{~kg} \mathrm{ha}^{-1}$ de nitrogênio, $60 \mathrm{~kg} \mathrm{ha}^{-1} \mathrm{de}_{2} \mathrm{O}_{5}$ e $60 \mathrm{~kg}$ $\mathrm{ha}^{-1}$ de $\mathrm{K}_{2} \mathrm{O}$ e a adubação de cobertura foi na fase de desenvolvimento V-6 (CASTIGLIONI et al., 1997), quando foram aplicados manualmente $30 \mathrm{~kg} \mathrm{ha}^{-1}$ de $\mathrm{N}$, na forma de sulfato de amônio e $2 \mathrm{~kg} \mathrm{ha}^{-1}$ de boro, na forma de bórax. Assim, o total aplicado de nutrientes por ha foi $40 \mathrm{~kg}$ de $\mathrm{N}, 60 \mathrm{~kg}$ de $\mathrm{P}_{2} \mathrm{O}_{5}, 60 \mathrm{~kg}$ de $\mathrm{K}_{2} \mathrm{O}$ e $2 \mathrm{~kg}$ de $B$.

A colheita, a debulha e a limpeza dos aquênios foram realizadas manualmente e o rendimento de aquênios foi calculado pela massa da parcela, corrigindo-se para umidade padrão de $11 \%$ e extrapolado para kg ha-1.

A extração do óleo foi realizada pelo método de Soxhlet, utilizando-se como solvente o éter de petróleo e calculando-se, em seguida, os resultados em porcentagem de base seca. A produção de óleo foi calculada utilizando-se o teor de óleo dos aquênios e a produção de aquênios e, como o teor de óleo foi calculado considerando-se 100\% de massa seca (base seca), o valor foi corrigido para $11 \%$ de umidade, multiplicando-se pelo fator 0,89 , cujo valor foi expresso em $k g \mathrm{ha}^{-1}$.

O delineamento experimental utilizado foi o de blocos ao acaso com quatro tratamentos e quatro repetições, em cada época de semeadura. Inicialmente, efetuou-se a análise de variância de cada experimento, isto é, em cada época de semeadura; logo após, realizouse a análise conjunta dos experimentos, com objetivo de testar a interação entre épocas e cultivares observando-se que o quociente entre o maior e o menor quadrado médio residual de cada variável, analisada em todos os ensaios (épocas) fosse igual ou menor que sete (PIMENTEL-GOMES \& GARCIA, 2002).

Para as análises de variância e comparação entre médias, utilizou-se o programa estatístico SISVAR (FERREIRA, 2003). As médias foram comparadas pelo teste de Scott-Knott, a 5\% de probabilidade. Para a interpretação dos índices de correlação (r), foram utilizadas as faixas de valores propostas por SHIKAMURA (2008), que estabelecem de 0 a 0,19 como "muito fraca”; 020 a 0,39 como "fraca”; 0,40 a 0,69 como "moderada”; 0,70 a 0,89 como “forte" e 0,90 a 1,00 como "muito forte". 


\section{RESULTADOS E DISCUSSÃO}

Para que o quociente entre o maior e o menor quadrado médio residual de cada variável, analisada em todos os ensaios fosse igual ou menor que sete, a $\mathrm{E}_{1}$ foi excluída para a análise conjunta dos experimentos para teor de óleo e, a $E_{6}$ para produção de aquênios e produção de óleo.

Na tabela 1, estão os valores da precipitação pluvial e, na tabela 2, da radiação solar que ocorreram nas épocas de semeaduras e períodos fenológicos, utilizados para estabelecer índices de correlação com a produção de aquênios, teor de óleo nos aquênios e produção de óleo.

Entre épocas de semeadura e cultivares para todas as variáveis estudadas, houve interação. De modo geral, nas quatro primeiras épocas (30/07, 17/08, 05/09, 24/09), ocorreram as maiores produções de aquênios (tabela 3), as quais estão dentro da época de semeadura recomendada para a Região de Ponta Grossa, que vai de 01/08 a 20/10 (IAPAR, 2009b).

A partir da $E_{5}(17 / 10)$, ocorreu diminuição expressiva na produção de aquênios, corroborando resultados obtidos por SANGOI \& KRUSE (1993), em Lages, SC, que obtiveram maiores respostas em produção de grãos nas semeaduras do final de julho, início de agosto e setembro. Da mesma forma, VEGA \& HALL (2002) concluíram que a produção de aquênios diminuiu acentuadamente quando a semeadura ocorreu em épocas tardias na Argentina.

Entre as cultivares, a melhor época de semeadura para produção de aquênios foi $E_{3}(05 / 09)$ para 'M734'; para 'Catissol', foram as épocas $E_{1}$ a $E_{3}$ (30/07 a 05/09); para ‘Aguará 4’, E a $_{4}$ (30/07 a 24/09); para 'Hélio 250', $E_{1}$ a $E_{5}$ (30/07 a 17/10), enquanto as cultivares 'M734' e 'Aguará 4' tiveram maiores produções de aquênios na maioria das épocas de semeadura. Entretanto, em épocas mais tardias (até a $E_{7}$, de 27/11) constatou-se as maiores produções para a cultivar 'M734'.

Entre a produção de aquênios e a precipitação pluvial no período da floração $\left(\mathrm{R}_{4}-\mathrm{R}_{6}\right)$, ocorreu forte correlação ( $r=0,73)$, corroborando vários autores (MERCAU et al., 2001; ERDEM \& DELIBAS, 2003; CASTRO \& FARIAS, 2005) que citaram a importância da disponibilidade hídrica neste período.

O teor de óleo diminuiu à medida que se retardaram as épocas de semeadura (Figura 1), não corroborando os resultados obtidos por SANGOI \& KRUSE, (1993), em trabalho conduzido no município de Lages, SC, com as cultivares 'Contissol 711' e 'DK 180’ em quatro épocas de semeadura (16/09/88 a 14/12/ 88), uma vez que não houve efeito significativo de época de semeadura sobre o teor de óleo dos aquênios das cultivares. No entanto, a amplitude das épocas estudadas pelos autores foi menor que a do presente trabalho, além de estarem próximas da época recomendada para a região.

A precipitação pluvial ocorrida na floração teve correlação forte $(\mathrm{r}=0,72)$ com o teor de óleo, comprovando, mais uma vez, a importância da disponibilidade hídrica no período de floração e enchimento de aquênios, citada por AGUIRREZÁBAL et al. (2001); ERDEM \& DELIBAS (2003); CASTRO \& FARIAS (2005); CASTRO et al. (2006).

Para a cultivar 'Hélio 250', observou-se o maior teor de óleo na maioria das épocas de semeadura e também a maior amplitude de redução com o avanço das épocas, variando de 51,8 a 37,4\% (Figura 1). O menor teor de óleo foi obtido com a cultivar 'M734' e

Tabela 1 - Soma das precipitações pluviais (mm) nos períodos fenológicos e ciclo total (média das cultivares) em cada época de semeadura. IAPAR, Estação Experimental de Ponta Grossa - PR, 2008.

\begin{tabular}{|c|c|c|c|c|c|}
\hline \multirow{2}{*}{ Épocas de semeadura } & \multicolumn{5}{|c|}{ 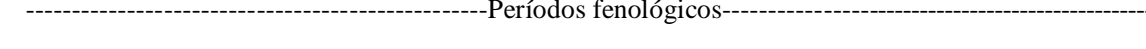 } \\
\hline & Semeadura - $\mathrm{R}_{1}$ & $\mathrm{R}_{1}-\mathrm{R}_{4}$ & $\mathrm{R}_{4}-\mathrm{R}_{6}$ & $\mathrm{R}_{6}-\mathrm{R}_{9}$ & Ciclo total \\
\hline$E_{1}(30 / 07 / 2007)$ & 62 & 50 & 149 & 55 & 316 \\
\hline$E_{2}(17 / 08 / 2007)$ & 56 & 97 & 120 & 135 & 408 \\
\hline$E_{3}(05 / 09 / 2007)$ & 94 & 194 & 97 & 117 & 502 \\
\hline$E_{4}(24 / 09 / 2007)$ & 180 & 37 & 173 & 108 & 498 \\
\hline$E_{5}(17 / 10 / 2007)$ & 221 & 187 & 94 & 80 & 582 \\
\hline $\mathrm{E}_{6}(07 / 11 / 2007)$ & 305 & 143 & 79 & 128 & 655 \\
\hline$E_{7}(27 / 11 / 2007)$ & 281 & 87 & 102 & 50 & 520 \\
\hline $\mathrm{E}_{8}(18 / 12 / 2007)$ & 184 & 112 & 28 & 76 & 400 \\
\hline $\mathrm{E}_{9}(07 / 01 / 2008)$ & 217 & 44 & 73 & 90 & 424 \\
\hline$E_{10}(28 / 01 / 2008)$ & 185 & 88 & 76 & 129 & 478 \\
\hline
\end{tabular}

$\mathrm{R}_{1}$ : aparecimento do broto floral; $\mathrm{R}_{4}$ : início da floração; $\mathrm{R}_{6}$ : final da floração; $\mathrm{R}_{9}$ : maturação fisiológica. 
Tabela 2 - Radiação solar (W m² ) nos períodos fenológicos e ciclo total (média das cultivares) em cada época de semeadura. IAPAR, Estação Experimental de Ponta Grossa - PR, 2008.

\begin{tabular}{|c|c|c|c|c|c|}
\hline \multirow{2}{*}{ Épocas de semeadura } & \multicolumn{5}{|c|}{ 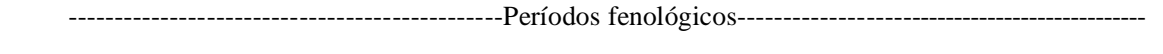 } \\
\hline & Semeadura $-\mathrm{R}_{1}$ & $\mathrm{R}_{1}-\mathrm{R}_{4}$ & $\mathrm{R}_{4}-\mathrm{R}_{6}$ & $\mathrm{R}_{6}-\mathrm{R}_{9}$ & Ciclo total \\
\hline $\mathrm{E}_{1}(30 / 07 / 2007)$ & 18933 & 7153 & 5317 & 13498 & 44901 \\
\hline$E_{2}(17 / 08 / 2007)$ & 17039 & 7000 & 4145 & 13642 & 41826 \\
\hline$E_{3}(05 / 09 / 2007)$ & 15552 & 8900 & 5982 & 12020 & 42454 \\
\hline$E_{4}(24 / 09 / 2007)$ & 16050 & 9810 & 4864 & 11763 & 42487 \\
\hline$E_{5}(17 / 10 / 2007)$ & 16050 & 10639 & 3773 & 10219 & 40681 \\
\hline$E_{6}(07 / 11 / 2007)$ & 16117 & 9055 & 4599 & 10155 & 39926 \\
\hline$E_{7}(27 / 11 / 2007)$ & 14800 & 7070 & 4884 & 7280 & 34034 \\
\hline$E_{8}(18 / 12 / 2007)$ & 12501 & 7884 & 4677 & 6391 & 31453 \\
\hline$E_{9}(07 / 01 / 2008)$ & 11671 & 8590 & 3227 & 7166 & 30654 \\
\hline $\mathrm{E}_{10}(28 / 01 / 2008)$ & 14358 & 6380 & 3958 & 5052 & 29748 \\
\hline
\end{tabular}

$\mathrm{R}_{1}$ : aparecimento do broto floral; $\mathrm{R}_{4}$ : início da floração; $\mathrm{R}_{6}$ : final da floração; $\mathrm{R}_{9}$ : maturação fisiológica.

também a menor amplitude de redução, variando de 42,6 a 34,7\%. IZQUIERDO et al. (2008) e DOSIO et al. (2000) constataram que os híbridos com aquênios listrados (como o 'M734'), que normalmente possuem menores teores de óleo que os negros (como o 'Hélio 250’) alcançaram a concentração máxima de óleo a níveis mais baixos de radiação solar ocorrida durante a fase de enchimento de aquênios. Assim, em épocas de semeaduras mais tardias, quando ocorre uma diminuição da quantidade de radiação solar devido à redução do comprimento do dia, híbridos listrados e negros tendem a ter menores diferenças de teor de óleo nos aquênios.

As maiores produções de óleo, principalmente nas quatro primeiras épocas de semeadura (fim de julho, agosto, início e fim de setembro) foram para a cultivar 'Aguará 4', que ficaram próximos a $1000 \mathrm{~kg} \mathrm{ha}^{-1}$ (tabela 4). De modo geral, entre todas as cultivares, nas quatro primeiras épocas de semeadura, obtiveram-se as maiores produções de óleo e, assim como ocorreu com as variáveis produção de aquênios e teor de óleo, a produção de óleo também teve correlação forte com a precipitação pluvial ocorrida na floração $(r=0,72)$.

Das variáveis climáticas estudadas, a radiação solar no período de enchimento de aquênios $\left(\mathrm{R}_{6}-\mathrm{R}_{9}\right)$ foi aquela com os maiores índices de correlação com produção de aquênios ( $(\mathrm{r}=0,93)$, teor de óleo $(\mathrm{r}=0,99)$ e produção de óleo $(\mathrm{r}=0,93)$, corroborando AGUIRREZÁBAL et al. (2001), quando afirmaram que a maior parte dos carboidratos utilizados para a síntese

Tabela 3 - Produção de aquênios (kg ha ${ }^{-1}$ ) das cultivares em cada época de semeadura. IAPAR, Estação Experimental de Ponta Grossa - PR, 2008.

\begin{tabular}{|c|c|c|c|c|c|}
\hline \multirow{2}{*}{ Épocas de semeadura } & \multicolumn{4}{|c|}{ 1----------------------------------------Cultivares-----------------------------------------' } & \multirow{2}{*}{ Média } \\
\hline & 'M734’ & ‘Aguará 4’ & 'Catissol’ & ‘Hélio 250’ & \\
\hline$E_{1}(30 / 07 / 2007)$ & $2134 \mathrm{~A} \mathrm{~b}$ & $2179 \mathrm{~A} \mathrm{a}$ & $1887 \mathrm{~B} \mathrm{a}$ & $1655 \mathrm{~B} \mathrm{a}$ & 1964 \\
\hline$E_{2}(17 / 08 / 2007)$ & $2153 \mathrm{~A} \mathrm{~b}$ & $2278 \mathrm{~A} \mathrm{a}$ & $1840 \mathrm{~B}$ a & $1830 \mathrm{~B} \mathrm{a}$ & 2025 \\
\hline$E_{3}(05 / 09 / 2007)$ & $2683 \mathrm{~A} \mathrm{a}$ & $2359 \mathrm{~B} \mathrm{a}$ & $1823 \mathrm{C} \mathrm{a}$ & $1752 \mathrm{C} \mathrm{a}$ & 2152 \\
\hline $\mathrm{E}_{4}(24 / 09 / 2007)$ & $2302 \mathrm{~A} \mathrm{~b}$ & $2544 \mathrm{~A} \mathrm{a}$ & 1574 B b & 1509 B a & 1982 \\
\hline$E_{5}(17 / 10 / 2007)$ & 1665 A c & $1691 \mathrm{~A} \mathrm{~b}$ & 1393 A b & $1649 \mathrm{~A} \mathrm{a}$ & 1599 \\
\hline$E_{7}(27 / 11 / 2007)$ & 1737 A c & 1236 B c & 1057 B c & 1026 B b & 1264 \\
\hline$E_{8}(18 / 12 / 2007)$ & $1220 \mathrm{Ad}$ & 1369 A c & 1032 B c & 933 B b & 1138 \\
\hline$E_{9}(07 / 01 / 2008)$ & $1280 \mathrm{Ad}$ & 1114 A c & 1004 A c & $825 \mathrm{~A} \mathrm{~b}$ & 1056 \\
\hline $\mathrm{E}_{10}(28 / 01 / 2008)$ & $1208 \mathrm{Ad}$ & $1476 \mathrm{~A} \mathrm{~b}$ & 706 B c & 787 B b & 1044 \\
\hline Média & 1820 & 1805 & 1368 & 1329 & 1581 \\
\hline
\end{tabular}

Médias seguidas de mesma letra maiúscula nas linhas e minúsculas nas colunas não diferem entre si pelo teste de Scott-Knott a 5\%; $\mathrm{CV}=14,0 \%$.

Ciência Rural, v.42, n.2, fev, 2012. 
Produção do girassol e teor de óleo nas sementes em diferentes épocas de semeadura no Centro-Sul do Paraná.

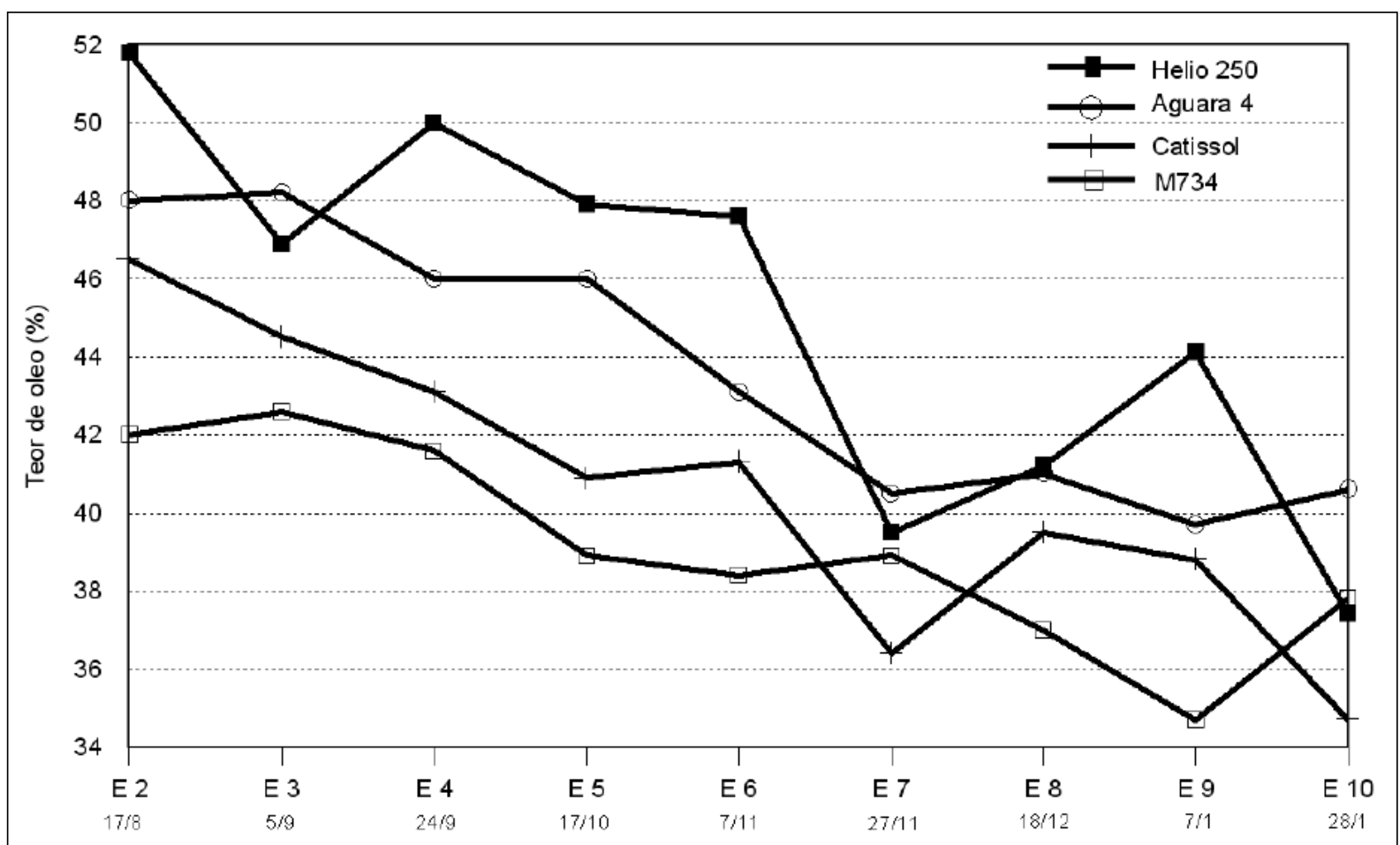

Figura 1 - Teor de óleo (\%) das cultivares, em cada época de semeadura (base seca). IAPAR, Estação Experimental de Ponta Grossa - PR, 2008.

de óleo e enchimento de grãos provém da fotossíntese contemporânea a tais processos e que o percentual de óleo é definido durante a etapa de enchimento dos aquênios. Da mesma forma, AGUIRREZÁBAL et al. (2003) verificaram que uma redução da radiação fotossinteticamente ativa interceptada pelo girassol durante a fase de enchimento de grãos afetou o peso da semente e a concentração de óleo.

\section{CONCLUSÃO}

As maiores produções de aquênios e de óleo são obtidas em semeaduras realizadas no final de julho, mês de agosto e de setembro. O teor de óleo dos aquênios é maior na semeadura de agosto, diminuindo nas épocas de semeadura mais tardias. Além disso, maiores quantidades de radiação solar no período de

Tabela 4 - Produção de óleo $\left(\mathrm{kg} \mathrm{ha}^{-1}\right)$ das cultivares em cada época de semeadura. IAPAR, Estação Experimental de Ponta Grossa - PR, 2008.

\begin{tabular}{|c|c|c|c|c|c|}
\hline \multirow{2}{*}{ Épocas de semeadura } & \multicolumn{4}{|c|}{ 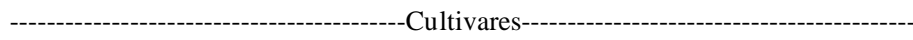 } & \multirow{2}{*}{ Média } \\
\hline & 'Aguará 4' & 'M734' & 'Hélio 250' & 'Catissol' & \\
\hline$E_{1}(30 / 07 / 2007)$ & $928 \mathrm{~A} \mathrm{a}$ & $864 \mathrm{~A} \mathrm{~b}$ & $717 \mathrm{~B} \mathrm{a}$ & $781 \mathrm{~B} \mathrm{a}$ & 823 \\
\hline$E_{2}(17 / 08 / 2007)$ & $976 \mathrm{~A} \mathrm{a}$ & 804 B b & $841 \mathrm{~B}$ a & $762 \mathrm{~B} \mathrm{a}$ & 846 \\
\hline$E_{3}(05 / 09 / 2007)$ & $1011 \mathrm{~A} \mathrm{a}$ & $1012 \mathrm{~A} \mathrm{a}$ & $770 \mathrm{~B}$ a & $720 \mathrm{~B} \mathrm{a}$ & 878 \\
\hline$E_{4}(24 / 09 / 2007)$ & $1040 \mathrm{~A} \mathrm{a}$ & 851 B b & $671 \mathrm{C} \mathrm{a}$ & $601 \mathrm{C} \mathrm{b}$ & 791 \\
\hline$E_{5}(17 / 10 / 2007)$ & $692 \mathrm{~A} \mathrm{~b}$ & 575 B c & $702 \mathrm{~A}$ a & 508 B c & 619 \\
\hline$E_{7}(27 / 11 / 2007)$ & $446 \mathrm{~B} \mathrm{c}$ & $602 \mathrm{~A} \mathrm{c}$ & 363 B b & $343 \mathrm{~B} \mathrm{~d}$ & 439 \\
\hline $\mathrm{E}_{8}(18 / 12 / 2007)$ & $450 \mathrm{~A} \mathrm{c}$ & $402 \mathrm{~A} \mathrm{~d}$ & $347 \mathrm{~A} \mathrm{~b}$ & $363 \mathrm{Ad}$ & 403 \\
\hline$E_{9}(07 / 01 / 2008)$ & 394 A c & $395 \mathrm{~A} \mathrm{~d}$ & $324 \mathrm{~A} \mathrm{~b}$ & $346 \mathrm{Ad}$ & 365 \\
\hline$E_{10}(28 / 01 / 2008)$ & $534 \mathrm{~A} \mathrm{c}$ & $410 \mathrm{~A} \mathrm{~d}$ & $264 \mathrm{~A} \mathrm{~b}$ & $218 \mathrm{Ad}$ & 357 \\
\hline Média & 725 & 657 & 555 & 516 & 613 \\
\hline
\end{tabular}

Médias seguidas de mesma letra maiúscula nas linhas e minúsculas nas colunas não diferem entre si pelo teste de Scott-Knott a 5\%; $\mathrm{CV}=15,0 \%$ 
enchimento dos aquênios e de chuva na floração elevam a produção de aquênios e o teor e produção de óleo dos aquênios.

\section{AGRADECIMENTOS}

Ao Instituto Agronômico do Paraná (IAPAR) e à Secretaria de Estado da Ciência, Tecnologia e Ensino Superior (SETI), pela estrutura e apoio financeiro para a realização dos trabalhos.

\section{REFERÊNCIAS}

AGUIRREZÁBAL, L.A.N. et al. La intercepción de la radiación lumínica. In: Girassol: aspectos fisiológicos que determinan el rendimiento. Buenos Aires: INTA, 2001. p.43-58.

AGUIRREZÁBAL, L.A.N. et al. Intercepted solar radiation during seed filling determines sunflower weight per seed and oil concentration. Crop Science Society of América, Madison, v.43, n.1, p.152-161, 2003. Disponível em: <https://www.soils.org/ publications/cs/articles/43/1/152>. Acesso em: 03 mar. 2011. doi 10.2135/cropsci2003.1520.

CASTIGLIONI, V.B.R. et al. Fases de desenvolvimento da planta de girassol. Londrina: EMBRAPA-CNPSo, 1997. 24p. (EMBRAPA-CNPSo. Documentos, 58).

CASTRO, C.; FARIAS, J.R.B. Ecofisiologia do girassol. In: LEITE, R.M.V.B.C.et al. (Ed). Girassol no Brasil. Londrina: Embrapa Soja, 2005. p.163-218.

CASTRO, C. et al. Boro e estresse hídrico na produção de girassol. Ciência e Agrotecnologia, Lavras, v.30, n.2, p.214220, 2006. Disponível em: <http://www.scielo.br/pdf/cagro/ v30n2/v30n2a04.pdf $>$. Acesso em: 03 mar. 2011.

DOSIO, G.A.A. et al. Solar radiation intercepted during seed filling and oil production in two sunflower hybrids. Crop Science Society of América, Madison, v.40, n.6, p.16371644, 2000. Disponível em: <https://www.soils.org/publications/ cs/articles/40/6/1637>. Acesso em: 03 mar. 2011.

ERDEM, T.; DELIBAS, L. Yield response of sunflower to water stress under tekirdag conditions. Helia, Tekirdag, v.26, n.38, p.149-158, 2003. Disponível em: <http://www.doiserbia.nb.rs/ img/doi/1018-1806/2003/1018-18060338149E.pdf>. Acesso em: 03 mar. 2011. doi: 10.2298/HEL0338149E.

FERREIRA, D.F. SISVAR software: versão 5.0 (Build 67). Lavras: DEX/UFLA, Universidade Federal de Lavras, 2003. Disponível em: <http://www.dex.ufla.br/ danielff/softwares.htm>. Acesso em: 15 out. 2011.
GAZZONI, D.L. Óleo de girassol como matéria-prima para biocombustíveis. In: LEITE, R.M.V.B.C. et al. (Ed). Girassol no Brasil. Londrina: Embrapa, 2005. p.145-161.

IAPAR. Instituto Agronômico do Paraná. Cartas climáticas do Paraná. Disponível em: <http://www.iapar.br/Sma/ Cartas_climaticas>. Acesso: 01 abr. 2009a.

IAPAR. Instituto Agronômico do Paraná. Girassol. Disponível em: <http://www.iapar.br/arquivos/File/folhetos/biodiesel/ girassol.html>. Acesso em: 01 abr. 2009b.

IZQUIERDO, N.G. et al. Weight per grain, oil concentration, and solar radiation intercepted during grain filling in black hull and striped hull sunflower hybrids. Crop Science Society of America, Madison, v.48, n.2, p.688-699, 2008. Disponível em: <http://crop.scijournals.org/cgi/content/full/48/2/688>. Acesso em: 17 ago. 2010.

MERCAU, J.L. et al. On-farm assessment of regional and seasonal variation in sunflower yield in Argentina. Agricultural Systems, Amsterdam, v.67, n.2, p.83-103, 2001. Disponível em: <http://www.sciencedirect.com/science/article/B6T3W41Y837G-2/2/51881e034c339447caa2dfe3d8f7eeb7>. Acesso em: 03 mar. 2011. doi: 10.1016/S0308-521X(00)00048-2.

PIMENTEL-GOMES, F.; GARCIA, C.A. Análise de grupos de experimentos. In: PIMENTEL-GOMES, F.; GARCIA, C.A (Ed). Estatística aplicada a experimentos agronômicos e florestais. Piracicaba: FEALQ, 2002. p.169-191.

SANGOI, L.; KRUSE, N.D. Comportamento de cultivares de girassol em diferentes épocas de semeadura no Planalto Catarinense. Pesquisa Agropecuária Brasileira, Brasília, v.28, n.1, p.8191, 1993. Disponível em: <http://webnotes.sct.embrapa.br/pab/ pab.nsf / 1369 a a 7 a 4 f 8 bbb 9 d 03256508004 f 4 e $1 \mathrm{~d} /$ f 31 d d c 8 d c 44 f 1346032567 d 00079 a d 4 a / \$ F I L E/ pab93_12_jan.pdf>. Acesso em: 03 mar.2011.

SANTOS, H.G. et al. Sistema brasileiro de classificação de solos. 2.ed. Rio de Janeiro: Embrapa Solos, 2006. 306p.

SHIKAMURA, S.E. Estatística II. Curitiba: Departamento de Estatística, UFPR. Disponível em <http://leg.ufpr.br/ silvia/ CE003/node74.html>. Acesso em: 31 jul. 2008.

VEGA, A.J.; HALL, A.J. Effects of planting date, genotype, and their interactions on sunflower yield - II. Components of oil yield. Crop Sciense Society of America, Madison, v.42, n.4, p.1202-1210, 2002. Disponível em: <https://www.crops.org/ publications/cs/articles/42/4/1202>. Acesso em: 03 mar. 2011. doi: $10.2135 /$ cropsci2002.1202. 